\title{
Effects of Hangeshashinto on Growth of Oral Microorganisms
}

\author{
Haruka Fukamachi, ${ }^{1}$ Chinami Matsumoto, ${ }^{2}$ Yuji Omiya, ${ }^{2}$ \\ Takafumi Arimoto, ${ }^{1}$ Hirobumi Morisaki, ${ }^{1}$ Hideo Kataoka, ${ }^{1}$ Miki Kadena, ${ }^{3}$ \\ Takahiro Funatsu, ${ }^{3}$ Masato Fukutake, ${ }^{2}$ Yoshio Kase, ${ }^{2}$ and Hirotaka Kuwata ${ }^{1}$ \\ ${ }^{1}$ Department of Oral Microbiology and Immunology, Showa University School of Dentistry, 1-5-8 Hatanodai, \\ Shinagawa-ku, Tokyo 142-8555, Japan \\ ${ }^{2}$ Tsumura Research Laboratories, Tsumura \& Co., 3586 Yoshiwara, Ami-machi, Inashiki-gun, Ibaraki 300-1192, Japan \\ ${ }^{3}$ Division of Dentistry for Persons with Disabilities, Department of Special Needs Dentistry, Showa University School of Dentistry, \\ 2-1-1 Kitasenzoku, Ohta-ku, Tokyo 145-8515, Japan \\ Correspondence should be addressed to Haruka Fukamachi; fharuka@dent.showa-u.ac.jp
}

Received 6 March 2015; Revised 5 June 2015; Accepted 8 June 2015

Academic Editor: Victor Kuete

Copyright (C) 2015 Haruka Fukamachi et al. This is an open access article distributed under the Creative Commons Attribution License, which permits unrestricted use, distribution, and reproduction in any medium, provided the original work is properly cited.

\begin{abstract}
Oral mucositis $(\mathrm{OM})$ in cancer patients induced by chemotherapy or radiotherapy has a significant impact on quality of life, and causes considerable morbidity. Oral microorganisms are likely to intensify the inflammatory process and aggravate the formation of ulcers. Hangeshashinto (HST), a Japanese kampo medicine, has been reported to be effective when used as a gargle for the treatment of OM. To clarify the effects of HST on oral microorganisms, we assessed its antimicrobial activity against 27 microbial species, including 19 oral bacteria and one fungus. HST extract inhibited the growth of Gram-negative bacteria, including Fusobacterium nucleatum, Porphyromonas gingivalis, Porphyromonas endodontalis, Prevotella intermedia, Prevotella melaninogenica, Tannerella forsythia, Treponema denticola, and Porphyromonas asaccharolytica, though inhibitory effects were less pronounced for Grampositive bacteria and the fungal strain. We then investigated the effects of antibacterial activities on 15 purified ingredients of HST and determined that baicalein, berberine, coptisine, [6]-shogaol, and homogentisic acid actively inhibited the growth of these bacteria. These findings showed that HST inhibits the growth of specific Gram-negative periodontopathogenic bacteria, which are significant pathogens in OM, without disturbing the normal oral flora. Our data suggest that HST may be a useful treatment for $\mathrm{OM}$ in patients undergoing anticancer treatment.
\end{abstract}

\section{Introduction}

Chemotherapy and radiotherapy produce side effects that have a major impact on the quality of life in patients while undergoing treatment. Oral mucositis $(\mathrm{OM})$ is one of the most frequently encountered side effects and commonly occurs 7-10 days after therapy. Pain associated with OM can prevent patients from eating, which results in a poorer treatment outcome. The complications arising from severe $\mathrm{OM}$ frequently require a temporary or complete cessation of therapy, thus preventing application or completion of the planned treatment dose. To date, a reliable treatment for $\mathrm{OM}$ has not been established.

Recently, a biological model for OM was proposed by Sonis, which revealed the complexity of pathogenesis of this disease [1]. The model described four successive phases in the disease process, an inflammatory (connective tissue) phase, followed by an epithelial phase, which leads to an ulcerative/bacteriological phase, and finally a healing phase. Oral microorganisms are thought to be involved in the ulcerative/bacteriological phase, where they are likely to intensify the inflammatory process and aggravate or promote the formation of ulcers [1-3]. In addition, the presence of OM may act as a portal of entry for oral microorganisms into the blood stream, leading to bacteremia and sepsis. Recent studies reported a relationship between the prevalence of oral pathologic condition and the occurrence of $\mathrm{OM}$ in patients undergoing anticancer therapy $[4,5]$. According to these reports, patients with gingivitis or periodontal disorders had high frequency of OM. In addition, Laheij et al. reported that 
there is a relationship between several periodontopathogenic bacteria, yeasts, and OM in patients being treated with highdose chemotherapy for hematopoietic stem cell transplant [6]. Therefore, we hypothesized that periodontopathogenic bacteria may aggravate the inflammatory process in OM.

Hangeshashinto (HST) is one of the Japanese "Kampo" medicines. HST is frequently used to treat acute or chronic gastrointestinal catarrh, fermentative diarrhea, and acute enterogastritis, and the mechanisms of the pharmacological effects have been partially elucidated. Recently, clinical trials demonstrated that an HST gargle had therapeutic effects in patient with chemotherapy-induced OM [7] and (chemo-) radiation-induced OM [8]. In addition, the study revealed that HST inhibited the increase in prostaglandin E2 (PGE2) production from IL- $1 \beta$ stimulated-human oral keratinocytes [9]. HST is composed of seven crude drugs, namely, pinellia tuber, scutellaria root, glycyrrhiza, jujube, ginseng, coptis rhizome, and processed ginger, all of which have medicinal properties. Coptis rhizome also has strong wide-spectrum antibacterial activity [10-12]. Therefore, in addition to the suppression of PGE2 production, the therapeutic effects of HST might also arise from antibacterial activity against oral microorganisms. By reducing the impact of the oral microorganisms, especially periodontopathogenic bacteria, HST might help reduce cancer therapy-related complications, as outlined in the four-stage model of OM.

The aims of this study were to assess the antimicrobial activity of HST extract and that of the purified active ingredients. We examined the antimicrobial activity of HST extract on the growth of 27 microbes, including 19 oral bacteria and one fungus. Furthermore, we studied the antibacterial effects of 15 purified ingredients contained in HST.

\section{Materials and Methods}

2.1. Bacterial Strains and Culture Conditions. The bacterial strains examined in this study and their culture conditions are listed in Supplementary Table 1 (see Supplementary Material available online at http://dx.doi.org/10.1155/2015/512947).

2.2. HST. HST (lot number 2100014010), containing seven crude drugs (Pinellia tuber (tuber of Pinellia ternata BREITENBACH, Araceae), scutellaria root (root of Scutellaria baicalensis GEORGI, Labiatae), glycyrrhiza (root or stolon of Glycyrrhiza uralensis FISCHER, Leguminosae), jujube (fruit of Zizyphus jujuba Miller var. inermis REHDER, Rhamnaceae), ginseng (root of Panax ginseng C.A. MEYER, Araliaceae), coptis rhizome (rhizome of Coptis japonica MAKINO, Ranunculaceae), and processed ginger (steamed rhizome of Zingiber officinale ROSCOE, Zingiberaceae)), was obtained from Tsumura \& Co. (Tokyo, Japan).

2.3. Preparation of HST Extract. HST was suspended in deionized water at $20 \mathrm{mg} / \mathrm{mL}$ and then stirred for $2 \mathrm{~h}$. The suspension was autoclaved at $121^{\circ} \mathrm{C}$ for $20 \mathrm{~min}$. After mixing for $10 \mathrm{~min}$, the suspension was centrifuged at $3,500 \times \mathrm{g}$ for $10 \mathrm{~min}$. The supernatant was collected for use as the stock solution and stored at $-20^{\circ} \mathrm{C}$ until use. The test solution was diluted to $10 \mathrm{mg} / \mathrm{mL}$ using culture medium.

2.4. Purified Ingredients from HST Extract. Fifteen purified active ingredients from HST were purchased from Tsumura \& Co. (Supplementary Table 2). Stock solutions (30 mM) were prepared for each chemical in $100 \%$ dimethyl sulfoxide (DMSO) and stored at $-80^{\circ} \mathrm{C}$ until use.

2.5. Minimum Inhibitory Concentration (MIC) and Minimum Bactericidal Concentration (MBC) Assays for HST. The MIC of HST against all 27 microbial species was determined using a 96-well plate dilution method. The $10 \mathrm{mg} / \mathrm{mL}$ test solution was prepared by two-fold serial dilution in each culture medium. Five concentrations were used within the $0.625-10 \mathrm{mg} / \mathrm{mL}$ range. The final inoculum concentrations were $1 \times 10^{4}$ colony-forming units $(\mathrm{CFU}) / \mathrm{mL}$ for Grampositive bacteria and the fungal strain and $1 \times 10^{5} \mathrm{CFU} / \mathrm{mL}$ for Gram-negative bacteria. The 96-well plates were incubated at $37^{\circ} \mathrm{C}$ for $24 \mathrm{~h}$ for Gram-positive bacteria and $48 \mathrm{~h}$ for Gram-negative bacteria. Medium without HST was used as a positive control. The MIC was defined as the lowest concentration that yielded no visible growth. The MBC of the test solution was determined by inoculating agar plates with the test solution mixture at a concentration representing the MIC, as well as at the next two higher concentrations. Experiments were performed in triplicate.

2.6. MIC and MBC Assays for 15 Purified Ingredients. The MIC of the 15 purified ingredients against F. nucleatum, Por. gingivalis, Por. endodontalis, Pre. intermedia, Pre. melaninogenica, Tan. forsythia, Tre. denticola, and Por. asaccharolytica was determined using the 96-well plate dilution method described above. Stock solutions $(30 \mathrm{mM})$ were diluted with each culture medium to prepare test solutions at concentrations of $100 \mu \mathrm{M}, 200 \mu \mathrm{M}$, and $300 \mu \mathrm{M}$. The $100 \mu \mathrm{M}$ test solutions were prepared by twofold serial dilution using each culture medium. Seven concentrations were used within the $1.56-100 \mu \mathrm{M}$ range at final DMSO concentrations of $0.005-$ $0.33 \%$. In case of Tan. forsythia, additional test solutions were used at concentrations of $200 \mu \mathrm{M}$ and $300 \mu \mathrm{M}$, with final DMSO concentrations of $0.67 \%$ and $1 \%$, respectively. The concentration of DMSO was less than $1 \%$ and thus did not affect the microbial growth. Wells containing $100 \mu \mathrm{L}$ of each dilution were inoculated with bacteria. The final inoculum concentrations were $1 \times 10^{5} \mathrm{CFU} / \mathrm{mL}$. The 96 -well plates were incubated at $37^{\circ} \mathrm{C}$ for $48 \mathrm{~h}$. Medium containing $0.33 \%, 0.67 \%$, and $1 \%$ DMSO was used as a control. The MIC was defined as the lowest antibiotic concentration that yielded no visible growth. The MBC of the test solution was determined using a method similar to that described above. Experiments were performed in at least quadruplicate.

2.7. Time-Kill Analysis of HST for Porphyromonas gingivalis. The time-kill analysis was determined as follows. Sample solutions, including culture broth and HST extract at a final concentration of $10 \mathrm{mg} / \mathrm{mL}$, were inoculated with bacterial suspension in triplicate. The final inoculum concentrations 
were $1 \times 10^{5} \mathrm{CFU} / \mathrm{mL}$. Controls containing no HST extract were also included. The number of viable bacterial cells was determined at 5, 10, 15, 60, and $120 \mathrm{~min}$ after inoculation by plating aliquots of undiluted and 10 -fold serially diluted sample onto $\mathrm{BHI} \mathrm{H} / \mathrm{M}$ plates. Plates were incubated for $72 \mathrm{~h}$ at $37^{\circ} \mathrm{C}$, and the resultant colonies were counted. Data from triplicate assays were averaged and plotted for each time point. All experimentation was carried out under anaerobic conditions $\left(10 \% \mathrm{CO}_{2}, 10 \% \mathrm{H}_{2}\right.$, and $\left.80 \% \mathrm{~N}_{2}\right)$.

\section{Results}

3.1. The Antibacterial Effect of HST. To determine whether the HST extract could inhibit the growth of oral microorganisms, we evaluated the antibacterial effect of HST against 27 microorganisms, including 19 oral bacteria and one fungus. A clear difference in susceptibility among species was observed (Table 1). The specific Gram-negative periodontopathogenic bacteria, including F. nucleatum, Por. gingivalis, Por. endodontalis, Pre. intermedia, Pre. melaninogenica, Tan. forsythia, Tre. denticola, and Por. asaccharolytica, were susceptible to HST extract and had low MICs $(<5 \mathrm{mg} / \mathrm{mL})$. However, the inhibitory effects of HST on Gram-positive bacteria and fungus were much less pronounced. The MICs and MBCs of HST extract are shown in Table 1.

3.2. The Antibacterial Effects of 15 Ingredients Contained in HST Extract. To identify the antimicrobial components of HST extract, the susceptibilities of F. nucleatum, Por. gingivalis, Por. endodontalis, Pre. intermedia, Pre. melaninogenica, Tan. forsythia, Tre. denticola, and Por. asaccharolytica to 15 ingredients present in HST extract were examined. Table 2 summarizes the antibacterial activity of these ingredients. From this analysis, baicalein, berberine, coptisine, [6]shogaol, and homogentisic acid were found to have antibacterial activity, whereas 10 other ingredients, including baicalin, wogonin, acteoside, [6]-gingerol, liquiritin, glycyrrhizic acid, ginsenoside Rgl, ginsenoside Rbl, corymboside, and cyclic AMP exerted no inhibitory effect on any of the strains. The MICs and MBCs of active ingredients are given in Table 2.

3.3. Time-Kill Analysis of HST against Por. gingivalis. The kinetics of the antibacterial activity of HST against the typical periodontopathogenic bacterium, Por. gingivalis ATCC33277, were examined. A representative time-kill profile is shown in Figure 1 . In treatments at the MIC $(2.5 \mathrm{mg} / \mathrm{mL})$, the number of viable cells did not decrease until $120 \mathrm{~min}$ after inoculation, and bacterial death was observed at $6 \mathrm{~h}$ after inoculation (data not shown). However, when the concentration reached four times the MIC $(10 \mathrm{mg} / \mathrm{mL})$, the number of viable cells decreased by approximately $40 \%$ after $5 \mathrm{~min}, 98 \%$ after $60 \mathrm{~min}$, and $100 \%$ after $120 \mathrm{~min}$ after inoculation.

\section{Discussion}

The aim of this study was to clarify the effects of HST on the survival of oral microorganisms. We first assessed the antimicrobial activity of HST extract against 27 microbial
TABLE 1: Minimal inhibitory concentrations (MIC) and minimal bactericidal concentrations (MBC) of HST extract.

\begin{tabular}{|c|c|c|}
\hline Bacterial strain & $\begin{array}{c}\mathrm{MIC} \\
(\mathrm{mg} / \mathrm{mL})\end{array}$ & $\begin{array}{c}\mathrm{MBC} \\
(\mathrm{mg} / \mathrm{mL})\end{array}$ \\
\hline \multicolumn{3}{|l|}{ Gram-negative oral bacteria } \\
\hline Aggregatibacter actinomycetemcomitans $\mathrm{Y} 4$ & $>10$ & $\mathrm{NT}^{*}$ \\
\hline Campylobacter rectus ATCC 33238 & $>10$ & $\mathrm{NT}^{*}$ \\
\hline Capnocytophaga ochracea ATCC27282 & $>10$ & $\mathrm{NT}^{*}$ \\
\hline Fusobacterium nucleatum ATCC25586 & 1.25 & 1.25 \\
\hline Porphyromonas gingivalis ATCC 33277 & 2.5 & 2.5 \\
\hline Porphyromonas gingivalis 381 & 1.25 & 1.25 \\
\hline Porphyromonas endodontalis ATCC 35406 & $<0.625$ & $<0.625$ \\
\hline Prevotella intermedia ATCC25611 & 2.5 & 2.5 \\
\hline Prevotella melaninogenica ATCC25845 & 2.5 & 2.5 \\
\hline Tannerella forsythia ATCC43037 & 5.0 & $\mathrm{ND}^{* *}$ \\
\hline Treponema denticola ATCC35405 & 5.0 & $\mathrm{ND}^{* *}$ \\
\hline Veillonella parvula ATCC17745 & $>10$ & $\mathrm{NT}^{*}$ \\
\hline \multicolumn{3}{|l|}{ Gram-negative bacteria } \\
\hline Bacteroides thetaiotaomicron JCM5827 & $>10$ & $\mathrm{NT}^{*}$ \\
\hline Campylobacter jejuni ATCC29428 & 10 & 10 \\
\hline Escherichia coli $\mathrm{K} 12$ & $>10$ & $\mathrm{NT}^{*}$ \\
\hline Porphyromonas asaccharolytica JCM6326 & 2.5 & 2.5 \\
\hline \multicolumn{3}{|l|}{ Gram-positive oral bacteria } \\
\hline Actinomyces viscosus ATCC19246 & $>10$ & $\mathrm{NT}^{*}$ \\
\hline Enterococcus faecalis 4532D & $>10$ & $\mathrm{NT}^{*}$ \\
\hline Lactobacillus casei JCM1133 & $>10$ & $\mathrm{NT}^{*}$ \\
\hline Streptococcus anginosus IS57 & $>10$ & $\mathrm{NT}^{*}$ \\
\hline Streptococcus gordonii ATCC10558 & $>10$ & $\mathrm{NT}^{*}$ \\
\hline Streptococcus mutans $109 \mathrm{c}$ & $>10$ & $\mathrm{NT}^{*}$ \\
\hline Streptococcus salivarius JCM5707 & $>10$ & $\mathrm{NT}^{*}$ \\
\hline \multicolumn{3}{|l|}{ Gram-positive bacteria } \\
\hline Bacillus subtilis ATCC 9372 & $>10$ & $\mathrm{NT}^{*}$ \\
\hline Bifidobacterium longum JCM1222 & 10 & $\mathrm{ND}^{* *}$ \\
\hline Staphylococcus aureus ATCC6738 & $>10$ & $\mathrm{NT}^{*}$ \\
\hline Streptococcus pyogenes ATCC12348 & $>10$ & $\mathrm{NT}^{*}$ \\
\hline \multicolumn{3}{|l|}{ Fungus } \\
\hline Candida albicans JCM2085 & $>10$ & $\mathrm{NT}^{*}$ \\
\hline
\end{tabular}

species, including 19 oral bacteria and one fungus. HST extract strongly inhibited the growth of Gram-negative periodontopathogenic bacteria such as F. nucleatum, Por. gingivalis, Por. endodontalis, Pre. intermedia, Pre. melaninogenica, Tan. forsythia, Tre. denticola, and Por. asaccharolytica, though it was less effective against Gram-positive bacteria and fungi. Donnelly et al. reported that, in cancer patients, the oral microbial balance can be disturbed by the cancer itself, the anticancer treatment, or the supportive therapies. All of these factors may contribute to a shift in the makeup of the microflora of the oral cavity from mainly Grampositive to predominantly Gram-negative bacteria [3]. The cell wall of Gram-negative bacteria contains the endotoxin lipopolysaccharide (LPS). LPS activates macrophages to produce inflammatory mediators. The disruption of the oral 
TABLE 2: Minimal inhibitory concentrations (MIC) and minimal bactericidal concentrations (MBC) of 15 purified compounds.

\begin{tabular}{|c|c|c|c|c|c|c|c|c|c|}
\hline & \multicolumn{9}{|c|}{$\mathrm{MIC} / \mathrm{MBC}(\mu \mathrm{M})$} \\
\hline & 1 & 2 & 3 & 4 & 5 & 6 & 7 & 8 & 9 \\
\hline Baicalin & - & - & - & - & - & - & - & - & - \\
\hline Baicalein & - & - & - & $25 / 25$ & $100 / 100$ & 25/ND & $300 / 300$ & - & $25 / 25$ \\
\hline Wogonin & - & - & - & - & - & - & - & - & - \\
\hline Acteoside & - & - & - & - & - & - & - & - & - \\
\hline Berberine & $100 / 100$ & $25 / 50$ & $50 / 50$ & $100 / 100$ & $25 / 25$ & $100 / 100$ & - & $25 / \mathrm{ND}$ & $100 / 100$ \\
\hline Coptisine & $50 / 50$ & $25 / 50$ & $50 / 50$ & $100 / 100$ & $25 / 25$ & $50 / 100$ & - & $12.5 / \mathrm{ND}$ & $100 / 100$ \\
\hline [6]-Shogaol & - & $50 / 50$ & $25 / 50$ & $25 / 25$ & $100 / 100$ & $50 / 100$ & - & - & $12.5 / 12.5$ \\
\hline [6]-Gingerol & - & - & - & - & - & - & - & - & - \\
\hline Liquiritin & - & - & - & - & - & - & - & - & - \\
\hline Glycyrrhizic acid & - & - & - & - & - & - & - & - & - \\
\hline Ginsenoside Rg1 & - & - & - & - & - & - & - & - & - \\
\hline Ginsenoside Rb1 & - & - & - & - & - & - & - & - & - \\
\hline Corymboside & - & - & - & - & - & - & - & - & - \\
\hline Homogentisic acid & - & - & - & - & $25 / 25$ & - & - & - & $12.5 / 12.5$ \\
\hline Cyclic AMP & - & - & - & - & - & - & - & - & - \\
\hline
\end{tabular}

-: not active; ND: not detected.

1: F. nucleatum; 2: P. gingivalis ATCC33277; 3: P. gingivalis 381; 4: P. endodontalis; 5: P. intermedia; 6: P. melaninogenica; 7: T. forsythia; 8: T. denticola; 9: P. asaccharolytica.

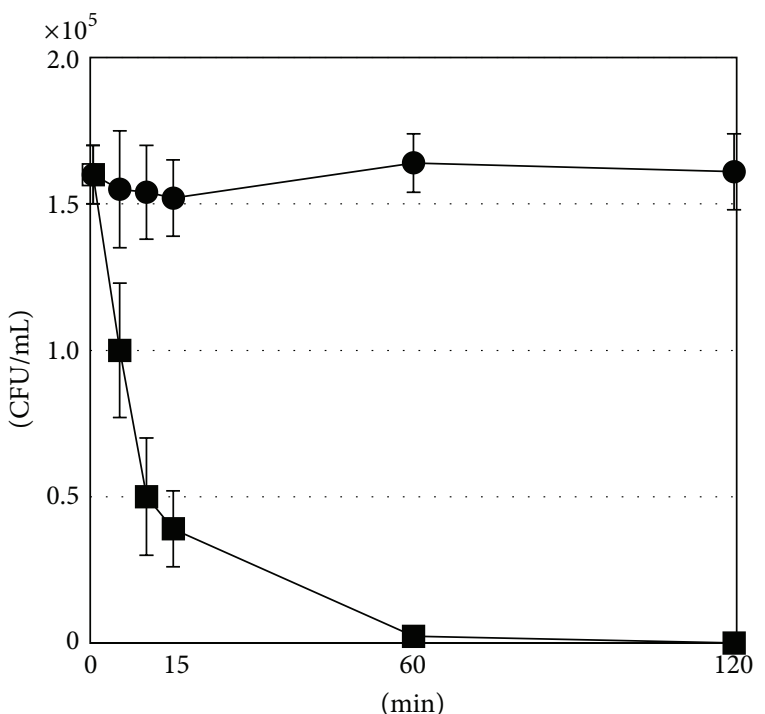

Figure 1: Time-kill curve of HST extract against Porphyromonas gingivalis ATCC33277. Data points represent the viable cell numbers in culture medium $(\bullet)$ or culture medium containing $10 \mathrm{mg} / \mathrm{mL}$ HST (घ). The experiment was performed in triplicate and data points are the means of 6 replicates \pm SD.

microbial balance may intensify the inflammatory process and aggravate or promote the formation of ulcers. Our present results indicated that HST extract might be useful for treatment of $\mathrm{OM}$, as it showed antibacterial activity specific to Gram-negative bacteria. Furthermore, these results indicated that HST may also be useful for treatment of periodontal disease.

HST is composed of seven crude drugs, including pinellia tuber, scutellaria root, glycyrrhiza, jujube, ginseng, coptis rhizome, and processed ginger, all of which contain crude drugs. A previous three-dimensional high-performance liquid chromatography analysis determined the broad chemical profile of HST. At least 30 ingredients were identified in the chromatogram (data not shown). We tested the antibacterial activity of 15 major ingredients of HST (baicalin, baicalein, wogonin, berberine, coptisine, [6]-shogaol, [6]-gingerol, liquiritin, glycyrrhizic acid, acteoside, ginsenoside Rgl, ginsenoside Rb1, corymboside, homogentisic acid, and cyclic AMP) towards F. nucleatum, Por. gingivalis, Por. endodontalis, Pre. intermedia, Pre. melaninogenica, Tan. forsythia, Tre. denticola, and Por. asaccharolytica, all of which were susceptible to HST extract. Of the 15 compounds, baicalein, berberine, coptisine, [6]-shogaol, and homogentisic acid showed antibacterial activity, although the activity differed between the bacterial species.

Isoquinoline alkaloid, berberine, and coptisine were highly active against $F$. nucleatum, Por. gingivalis, Por. endodontalis, Pre. intermedia, Pre. melaninogenica, Tre. denticola, and Por. asaccharolytica, though no inhibitory effect was observed on the growth of Tan. forsythia. Species-specific inhibition by berberine has been reported previously [11, 13]. According to these reports, Por. gingivalis, Pre. intermedia, and $F$. nucleatum were susceptible to berberine at an MIC range of $13-50 \mu \mathrm{g} / \mathrm{mL}(35-134 \mu \mathrm{M})$, which agrees with the findings of the current study. In addition, our study revealed that several Gram-negative periodontopathogenic bacteria, including Por. endodontalis, Pre. melaninogenica, and Tre. denticola, are susceptible to berberine at a similar MIC range. HST extract also contained the alkaloid coptisine, the inhibitory activity of which was approximately equal to that of berberine. Except for Tre. denticola, the MBC values were in the same range as those of the MIC values for all microbial species, indicating that berberine and coptisine likely have bactericidal activity. 
Interestingly, [6]-shogaol exhibited species-specific antibacterial activity against the Prevotella and Porphyromonas strains, while [6]-gingerol did not inhibit the growth of these species. The major active ingredients of processed ginger are gingerol and shogaol. Processed ginger has received extensive attention due to its antioxidant and anti-inflammatory activities [14]. Thermal processing of gingerols gives shogaols, which frequently show greater anticancer activity than their precursors $[15,16]$. Similarly, in the current study, [6]-shogaol more effectively inhibited bacterial growth than [6]-gingerol. Despite this, Park et al. reported that [10]-, [12]-gingerol could inhibit the growth of Por. gingivalis, Por. endodontalis, and Pre. intermedia at an MIC range of $6-30 \mu \mathrm{g} / \mathrm{mL}(21-107 \mu \mathrm{M})$ and an MBC range of $4-20 \mu \mathrm{g} / \mathrm{mL}(14-71 \mu \mathrm{M})$ [17].

Baicalein is the common name for 5,6,7-trihydroxyflavone. In the current study, baicalein showed antibacterial activity towards all Porphyromonas and Prevotella species, except Por. gingivalis, and was the only compound with activity against Tan. forsythia. Baicalein is an aglycone of baicalin, but baicalin did not inhibit the growth of any of the tested bacteria.

Homogentisic acid is a phenolic acid. Recently, Lebouvier et al. reported that homogentisic acid has antiplasmodial activity, mediated through inhibition of Pfnek-1, which is a specific protein kinase of Plasmodium falciparum [18]. However, little is known about the antibacterial activity. For all of the ingredients identified here, the mechanisms of antibacterial activity remain unknown.

Kono et al. reported that the concentrations of baicalein, berberine, and [6]-shogaol in $10 \mathrm{mg} / \mathrm{mL}$ HST extracts were $8.56 \mu \mathrm{g} / \mathrm{mL}(32 \mu \mathrm{M}), 37.59 \mu \mathrm{g} / \mathrm{mL}(112 \mu \mathrm{M})$, and $1.63 \mu \mathrm{g} / \mathrm{mL}$ $(5.9 \mu \mathrm{M})$, respectively [9]. This suggests that the antibacterial activity of HST extract can be mainly attributed to berberine. In our study, Por. gingivalis, Por. endodontalis, Por. asaccharolytica, Pre. intermedia, Pre. melaninogenica, Tre. denticola, and F. nucleatum were susceptible to berberine at an MIC range of $25-100 \mu \mathrm{M}$. Except for Tre. denticola, the MBC for berberine-susceptible bacteria was in the range of 25-100 $\mu \mathrm{M}$. This indicates that the antibacterial activity of berberine is effectively bactericidal. The MIC of baicalein for Tan. forsythia was $300 \mu \mathrm{M}$, whereas the baicalein concentration in HST extract was only $32 \mu \mathrm{M}$. These results raise the possibility that other antibacterial ingredients are present in HST or that an antibacterial effect is provided by the combination of ingredients.

A cell viability assay using human oral keratinocytes demonstrated that HST extract may not induce a cytotoxic effect at $10 \mathrm{mg} / \mathrm{mL}$ at $30 \mathrm{~min}$ after inoculation but that cell viability was significantly affected by the $60 \mathrm{~min}$ time point (Supplementary Figure 1). On the other hand, the survival of Por. gingivalis was dramatically decreased at HST concentrations greater than four times the MIC at $15 \mathrm{~min}$ after inoculation. After a patient with $\mathrm{OM}$ has rinsed with HST, a gradual decrease in HST concentration may occur in the oral cavity due to dilution by saliva. Further studies are needed to determine a HST concentration that may inhibit bacterial growth without affecting the survival of oral cells in vivo. In addition, the oral cavity is heavily colonized by a complex, relatively specific, and highly interrelated group of microorganisms that are organized in biofilms. Biofilms can be more resistant to antimicrobials than planktonic cells from the same species. Further studies should evaluate whether the antibacterial activity of HST is maintained against bacteria present in a biofilm.

The complexity of the pathogenesis of $\mathrm{OM}$ in cancer patients has been revealed. However, interventions that target only one aspect of the OM biological phase have been reported to be largely ineffective [19]. Treatments of $\mathrm{OM}$ in cancer patients should be directed toward multiple biological targets of OM process. Kono et al. reported that HST strongly suppresses PGE2. The present study showed that HST exhibited antibacterial activity against Gramnegative periodontopathogenic bacteria and that ingredients in HST extract may play a role in inhibiting the growth of oral bacteria. Although the mechanism of inhibition of bacterial growth is not fully understood, the data from this investigation indicated a potential application for HST as a therapeutic agent for the prevention of the Gram-negative periodontopathogenic bacterial infection in OM.

\section{Disclaimer}

The authors are fully responsible for the content of this paper.

\section{Conflict of Interests}

C. Matsumoto, Y. Omiya, M. Fukutake, and Y. Kase are employed by Tsumura \& Co. H. Fukamachi, T. Arimoto, H. Morisaki, H. Kataoka, M. Kadena, and T. Funatsu have nothing to declare.

\section{Authors' Contribution}

All authors reviewed and approved the paper.

\section{Acknowledgment}

This work is dedicated in fondest memory to Professor Takeshi Igarashi, whose influence as a mentor will be greatly missed and without whom this work would not have been possible. Hirotaka Kuwata received grant support from Tsumura \& Co.

\section{References}

[1] S. T. Sonis, "The pathobiology of mucositis," Nature Reviews Cancer, vol. 4, no. 4, pp. 277-284, 2004.

[2] N. Al-Dasooqi, S. T. Sonis, J. M. Bowen et al., "Emerging evidence on the pathobiology of mucositis," Supportive Care in Cancer, vol. 21, no. 11, pp. 3233-3241, 2013.

[3] J. P. Donnelly, L. A. Bellm, J. B. Epstein, S. T. Sonis, and R. P. Symonds, "Antimicrobial therapy to prevent or treat oral mucositis," The Lancet Infectious Diseases, vol. 3, no. 7, pp. 405412, 2003.

[4] L. L. D. Fernandes, S. R. Torres, M. Garnica et al., "Oral status of patients submitted to autologous hematopoietic stem cell 
transplantation," Supportive Care in Cancer, vol. 22, no. 1, pp. 15-21, 2014.

[5] A. Khaw, R. Logan, D. Keefe, and M. Bartold, "Radiationinduced oral mucositis and periodontitis-proposal for an inter-relationship," Oral Diseases, vol. 20, no. 3, pp. e7-e18, 2014.

[6] A. M. G. A. Laheij, J. J. de Soet, P. A. von Dem Borne et al., "Oral bacteria and yeasts in relationship to oral ulcerations in hematopoietic stem cell transplant recipients," Supportive Care in Cancer, vol. 20, no. 12, pp. 3231-3240, 2012.

[7] T. Kono, M. Satomi, N. Chisato et al., "Topical application of hangeshashinto (TJ-14) in the treatment of chemotherapyinduced oral mucositis," World Journal of Oncology, vol. 1, pp. 232-235, 2010.

[8] T. Yamashita, K. Araki, M. Tomifuji, D. Kamide, Y. Tanaka, and A. Shiotani, "A traditional Japanese medicine-Hangeshashinto (TJ-14) - alleviates chemoradiation-induced mucositis and improves rates of treatment completion," Supportive Care in Cancer, vol. 23, no. 1, pp. 29-35, 2015.

[9] T. Kono, A. Kaneko, C. Matsumoto et al., "Multitargeted effects of hangeshashinto for treatment of chemotherapy-induced oral mucositis on inducible prostaglandin E2 production in human oral keratinocytes," Integrative Cancer Therapies, vol. 13, no. 5, pp. 435-445, 2014.

[10] S. Higaki, Y. Hasegawa, M. Morohashi, and Y. Takayoshi, "The correlation of Kampo formulations and their ingredients on anti-bacterial activities against Propionibacterium acnes," Journal of Dermatology, vol. 22, no. 1, pp. 4-9, 1995.

[11] J. P. Hu, N. Takahashi, and T. Yamada, "Coptidis rhizoma inhibits growth and proteases of oral bacteria," Oral Diseases, vol. 6, no. 5, pp. 297-302, 2000.

[12] F. Ma, Y. Chen, J. Li et al., "Screening test for anti-Helicobacter pylori activity of traditional Chinese herbal medicines," World Journal of Gastroenterology, vol. 16, no. 44, pp. 5629-5634, 2010.

[13] Q. Xie, B. R. Johnson, C. S. Wenckus, M. I. Fayad, and C. D. $\mathrm{Wu}$, "Efficacy of berberine, an antimicrobial plant alkaloid, as an endodontic irrigant against a mixed-culture biofilm in an in vitro tooth model," Journal of Endodontics, vol. 38, no. 8, pp. 1114-1117, 2012.

[14] H. W. Jung, C.-H. Yoon, K. M. Park, H. S. Han, and Y.-K. Park, "Hexane fraction of Zingiberis Rhizoma Crudus extract inhibits the production of nitric oxide and proinflammatory cytokines in LPS-stimulated BV2 microglial cells via the NFkappaB pathway," Food and Chemical Toxicology, vol. 47, no. 6 , pp. 1190-1197, 2009.

[15] J. S. Kim, S. I. Lee, H. W. Park et al., "Cytotoxic components from the dried rhizomes of Zingiber officinale Roscoe," Archives of Pharmacal Research, vol. 31, no. 4, pp. 415-418, 2008.

[16] S. Sang, J. Hong, H. Wu et al., "Increased growth inhibitory effects on human cancer cells and anti-inflammatory potency of shogaols from Zingiber officinale relative to gingerols," Journal of Agricultural and Food Chemistry, vol. 57, no. 22, pp. 1064510650, 2009.

[17] M. Park, J. Bae, and D.-S. Lee, "Antibacterial activity of [10]gingerol and [12]-gingerol isolated from ginger rhizome against periodontal bacteria," Phytotherapy Research, vol. 22, no. 11, pp. 1446-1449, 2008.

[18] N. Lebouvier, V. Jullian, I. Desvignes et al., "Antiplasmodial activities of homogentisic acid derivative protein kinase inhibitors isolated from a vanuatu marine sponge Pseudoceratina sp.", Marine Drugs, vol. 7, no. 4, pp. 640-653, 2009.
[19] M. A. Stokman, F. K. L. Spijkervet, H. M. Boezen, J. P. Schouten, J. L. N. Roodenburg, and E. G. E. De Vries, "Preventive intervention possibilities in radiotherapy- and chemotherapyinduced oral mucositis: results of meta-analyses," Journal of Dental Research, vol. 85, no. 8, pp. 690-700, 2006. 


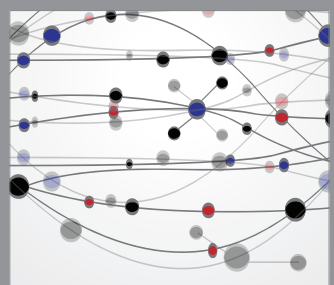

The Scientific World Journal
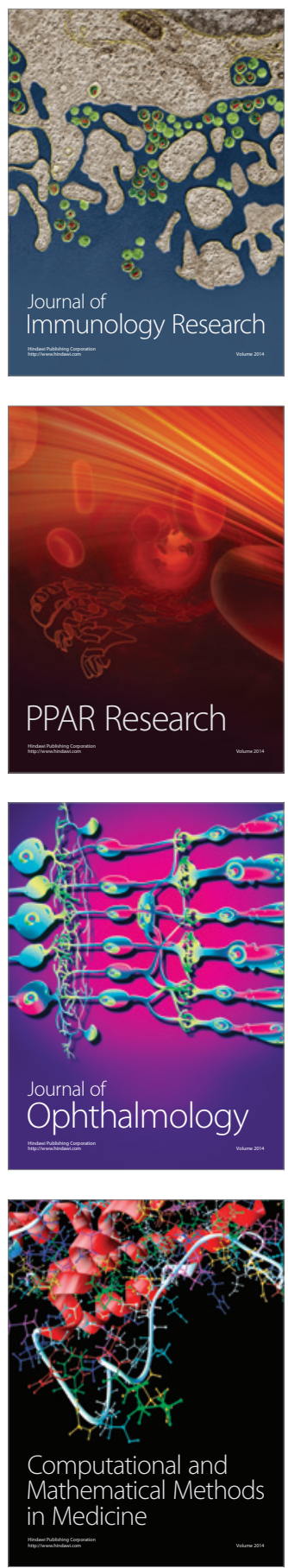

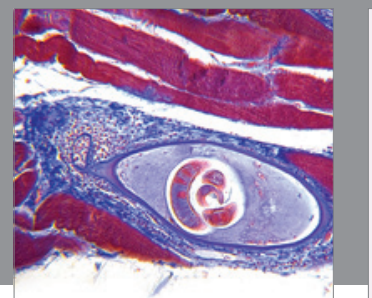

Gastroenterology

Research and Practice
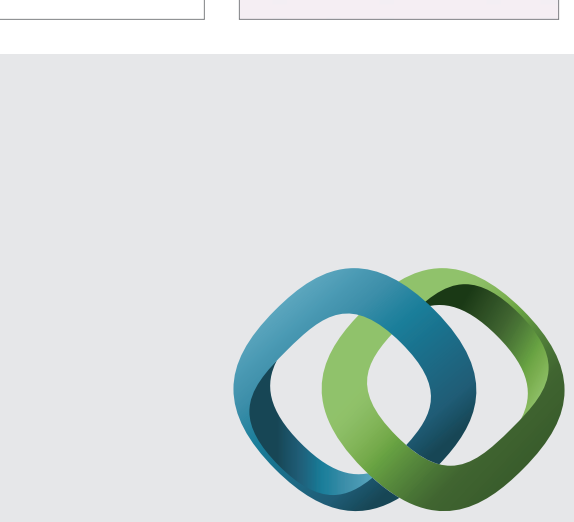

\section{Hindawi}

Submit your manuscripts at

http://www.hindawi.com
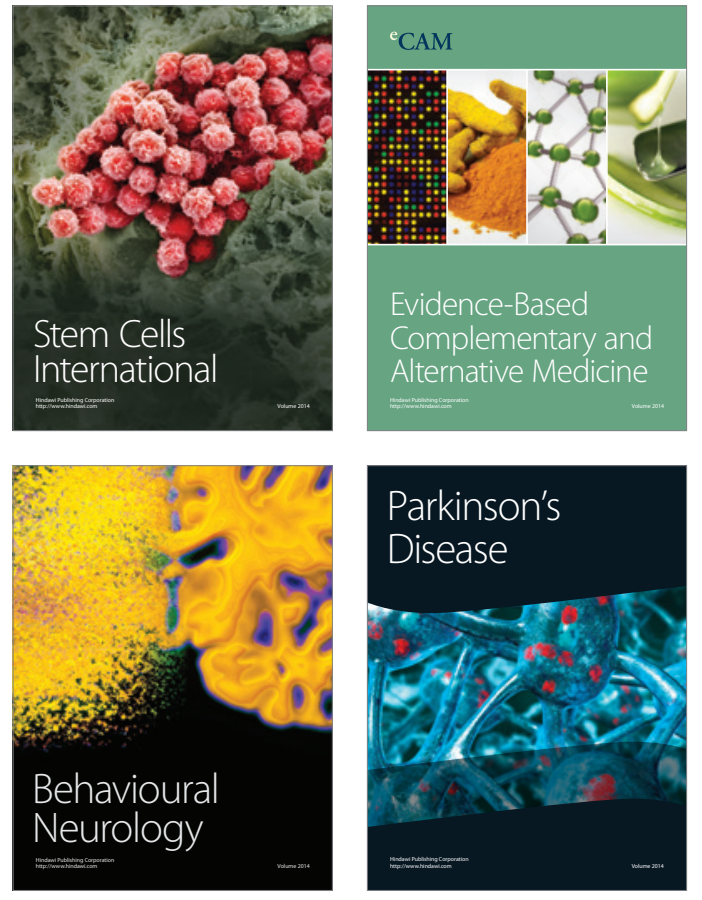
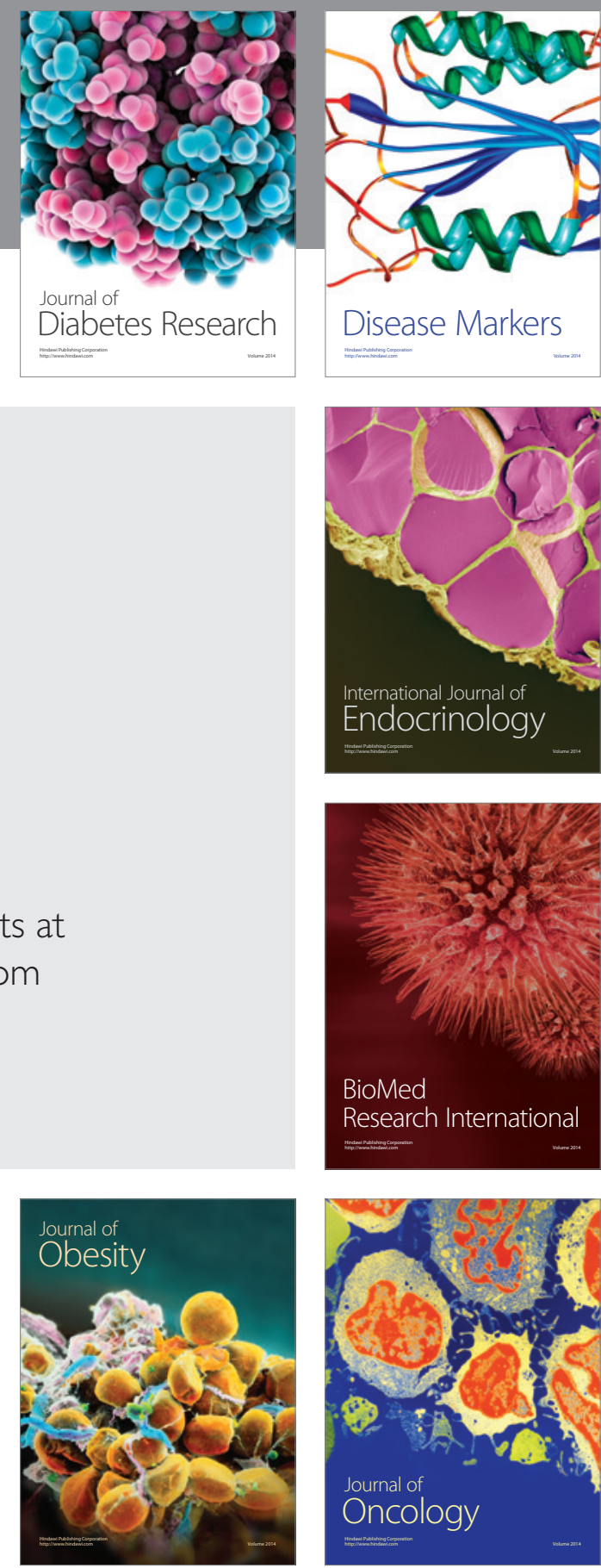

Disease Markers
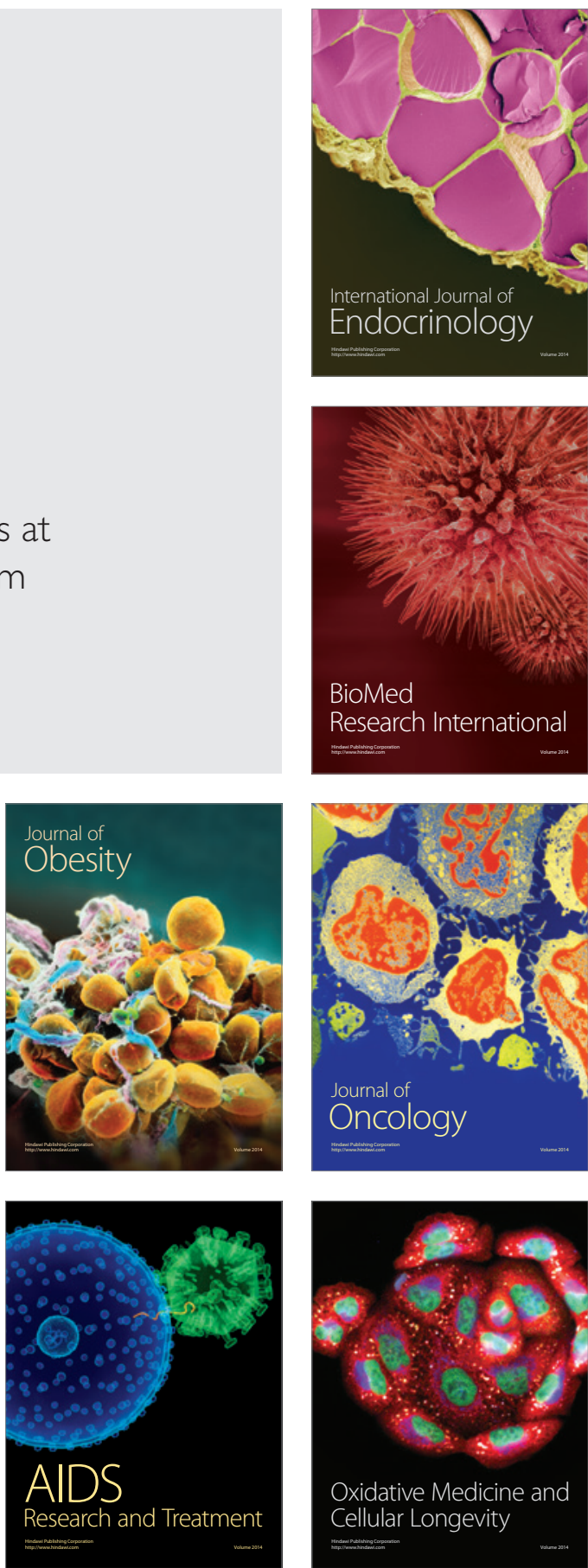